\title{
Sedation and analgesia practices at Italian neonatal intensive care units: results from the EUROPAIN study
}

\author{
Paola Lago ${ }^{1 *}$, Anna Chiara Frigo ${ }^{2}$, Eugenio Baraldi ${ }^{1}$, Roberta Pozzato ${ }^{1}$, Emilie Courtois $^{3}$, Jérôme Rambaud ${ }^{4}$, \\ Kanwaljeet J. S. Anand ${ }^{5}$ and Ricardo Carbajal $\left.\right|^{3,6}$
}

\begin{abstract}
Background: We aimed to examine current bedside analgesia/sedation (A/S) and pain assessment (PA) practices in Italian neonatal intensive care units (NICUs) in relation to the findings of an epidemiological European study and recently-introduced national guidelines.

Methods: We analyzed the Italian data from the EUROPAIN (EUROpean-Pain-Audit-In-Neonates) prospective observational study on A/S practices that involved 6680 newborns admitted to tertiary-level NICUs in 18 European countries. Demographics, type of assisted ventilation, type and mode of A/S administration and PA were analyzed. Multivariate linear regression models were used to identify factors predicting A/S and PA practices.

Results: From October $1^{\text {st }}, 2012$ to June $30^{\text {th }}, 2013$, thirty Italian NICUs gathered data on 422 newborn: 131 on invasive ventilation (IV); 150 on noninvasive ventilation (NIV); and 141 on spontaneous ventilation (SV). A/S was documented for $35.3 \%$ of all infants admitted (86.3\% IV; $17.3 \% \mathrm{NIV} ; 7.1 \% \mathrm{SV}[p=0.0001])$, and varied considerably between NICUs (as reported in other European countries). Strong analgesics were used in 32.5\% of cases, sedatives in $10.2 \%$, mild analgesics in $3.8 \%$. Fentanyl was used in $78.6 \%$ of cases, morphine in $8.4 \%$, neuromuscular blockers in $5.3 \%$, midazolam in $22.1 \%$. The performance of PA was documented in $67.5 \%$ of all newborn $(85.5 \% \mathrm{IV} ; 67.3 \% \mathrm{NIV}$; $51.1 \%$ SV $[p=0.001])$. Illness severity, type of ventilation, bedside PA, and number of NICU beds were all factors associated with A/S use on multivariate analysis, while gestational age $\leq 32$ weeks, and type of ventilation and presence of a pain team were associated with PA.
\end{abstract}

Conclusions: We documented a generally widespread, but still highly variable use of A/S and PA at Italian NICUs, despite the diffusion of national guidelines. There is an urgent need to improve routine PA to enable customized pain and stress control (and prevention) in all infants.

Trial registration: Clinical Trials.gov \# NCT01694745.

Keywords: Pain, Newborn and preterm, Analgesic, Sedative, Opioids, Pain assessment

\section{Background}

The use of analgesia and sedation $(\mathrm{A} / \mathrm{S})$ in newborns has increased largely in the last 25 years since it was demonstrated that failure to administer analgesics during neonatal anesthesia increased infants' stress hormone response, time to recovery, and mortality rates $[1,2]$.

\footnotetext{
* Correspondence: paola.lago@aopd.veneto.it

${ }^{1}$ Neonatal Intensive Care Unit, Women's and Children's Health Department, Azienda Ospedaliera-University of Padova, Via Giustiniani 3, Padua 35128, Italy

Full list of author information is available at the end of the article
}

Researchers also showed that the exposure of term and preterm newborns to uncontrolled and repetitive pain is most common in intensive care units [3] and may affect the infants' pain perception in later infancy [4], and impair their neurodevelopmental outcome in terms of cognition [5], motor function [6] and brain development $[7,8]$.

Further studies demonstrated the efficacy of A/S during mechanical ventilation in reducing pain scores, but they were unable to demonstrate any impact on neurodevelopmental outcome or survival [9]. Some concerns have also 
been raised concerning the potential toxicity of strong analgesics, sedatives and anesthetic drugs in the neonatal period, prompting a more judicious use of these drugs at this crucial time for brain development [10, 11]. There have been reports of analgesic therapy prolonging the need for mechanical ventilation, delaying feeding [12], and possibly contributing to other sequelae, including impaired brain growth, altered eye-hand coordination, and weak short-term memory $[13,14]$.

Since the early 2000s, scientific societies and consensuses on pain control and prevention in the newborn have recommended using pharmacological and non-pharmacological interventions for all painful and stressful neonatal procedures, and routine pain assessments (PA) to enable analgesic intervention to be customized appropriately [15-17]. How much these best practices have been implemented remains unclear, however. In 2005 and 2010, we investigated this issue at Italian NICUs. Despite a widespread (albeit variable) use of $\mathrm{A} / \mathrm{S}$, we identified a very limited routine use of PA, and concluded that there remained an urgent need to implement routine PA in all newborn infants to better customize $\mathrm{A} / \mathrm{S}$ in clinical practice [18-20].

The EUROPAIN survey is the first study, to our knowledge, to have prospectively recorded round-the-clock bedside A/S and PA practices for all NICU admissions over a defined period of time, generating a precise picture of these practices [21].

We analyzed, in detail, the Italian data obtained for the EUROPAIN survey to document and compare current $\mathrm{A} / \mathrm{S}$ practices at Italian NICUs vis-à-vis their counterparts elsewhere in Europe and the latest national guidelines [22].

\section{Methods}

\section{Study design and participants}

The EUROPAIN (EUROpean-Pain-Audit-In-Neonates) survey was a prospective observational study on A/S management in NICU patients in 18 European countries. Details of the study are available at http://www.europainsurvey.eu/. Principal Investigators were appointed in each country to coordinate the study and contact all eligible tertiary-level NICUs (responsible for the care of critically-ill newborn of all gestational ages, that manage the full period of invasive ventilation). Coordinators of the nursing staff and physicians at each unit provided their general statistics and existing A/S protocols for the newborn. The national Principal Investigator also provided details of any national guidelines for treating or preventing neonatal pain.

\section{Data collection}

All neonates up to 44 weeks post-conceptional age newly admitted to eligible Italian NICUs during the enrollment period were considered. Data were collected prospectively on each infant (demographics; modes of ventilation; use of continuous or intermittent/bolus sedation, analgesics or neuroblockers; drug withdrawal and pain assessment using any validated pain scale) for the first 28 days in hospital, or until death, discharge, or transfer to another hospital. Neonates were classified as belonging to the A/S group if they received at least one dose of such medication; the duration of $\mathrm{A} / \mathrm{S}$ infusions or number of boluses were also recorded. As for PA, the NICUs were asked to specify what tools were used and the number of daily pain assessments. Neonates were deemed as assessed if at least one pain assessment was performed. Units recruited patients over a one-month period and data were collected on standardized paper questionnaires, then entered in online questionnaires. Each unit also kept a logbook of all neonates admitted during the study period. A centralized team in Paris monitored the completeness and relevance of the data entered in the study database, as reported in an earlier publication [21]. After obtaining the approval of the regulatory bodies for the Protection of Human Subjects, Data Protection, and Health Research Data Management in France, the study was also approved by the local ethical committees of the participating hospitals. Written informed consent was obtained from the parents of the infants involved.

The study was registered at ClinicalTrials.gov (\#NCT01694745).

\section{Statistical analyses}

The study population's clinical characteristics were described in terms of numbers and percentages for categorical variables, medians with interquartile ranges for quantitative variables since not normally distributed (normality evaluated with Kolmogorov-Smirnov test). The distributions of patients' clinical characteristics by A/S practices implemented were compared with the chi-square or Fisher's exact test for categorical variables, and with Kruskal-Wallis rank sum test for quantitative variables because their distribution was not normal. Type and modality of A/S were compared between age groups $(\leq 32 />32)$ with the $\backslash$ chisquare or Fisher's exact test. Predictors of A/S use and of PA were identified by means of a univariate hierarchical logistic regression model (SAS PROC GLIMMIX). The hierarchical model was adopted to take into account patient clustering at different units, considering the NICU as a random factor. We used model-building methods to obtain the best fit and the most parsimonious model. Laplace's method was used to test the model's fit by examining the change in the -2LL between models with the chi-square difference test. The variables identified as potential predictors in the univariate analyses to consider in the multivariate model were: gestational age $(\leq 32 />32$ weeks), sex, severity of illness (Clinical Risk Index for Babies [CRIB] score, validated for all NICU admissions) [22], age on admission ( $\leq 6 />6$ h), 5-min Apgar score $(<5 / \geq 5)$, type of 
respiratory support, use of pain scales (for A/S use), presence of a pain specialist (physician or nurse) and pain team, presence of local written guidelines for pain (assessment and control), and characteristics of the NICUs in terms of numbers of beds $(<15 / \geq 15)$ and yearly admissions.

The results of the regression analyses are presented as odds ratios (OR) with two-sided 95\% confidence intervals (CI).

Multicollinearity was checked with Variance Inflation Factor (VIF) and it was slightly above 1 indicating that multicollinearity was not present.

The statistical analyses were conducted with the SAS statistical package for Windows, release 9.4 (SAS Institute Inc., Cary, NC, USA).

\section{Results}

\section{Study population}

From October $1^{\text {st }}, 2012$ to June $30^{\text {th }}, 2013,70$ tertiarylevel Italian NICUs meeting the above-defined entry criteria were invited to participate in the survey. Thirty
(42.8\%) accepted to join the study, but only 28 completed the data submission process. Of the 468 neonates enrolled, 46 were excluded, leaving a final sample of 422 newborns. Based on the highest level of respiratory support neonates received during their NICU stay, they were divided into three groups: 131 on invasive ventilation (IV); 150 on noninvasive ventilation (NIV); and 141 on spontaneous ventilation (SV). Figure 1 shows the trial flowchart.

Table 1 shows the study population's demographics and clinical characteristics.

Most of the NICUs had local guidelines for controlling procedural and prolonged pain $(n=23[82.1 \%])$, for preventing and treating neonatal abstinence syndrome $(n=20[71.4 \%])$, and for pain monitoring $(n=23$ [78.6\%]); futhermore $82.1 \%$ of the units reported performing routine pain assessments. There was a doctor $(n=23[82.1 \%])$ and/or a nurse $(n=15$ [71.4\%]) responsible for pain treatment at the NICU, while pain teams were less common $(n=15[53.6 \%])$.

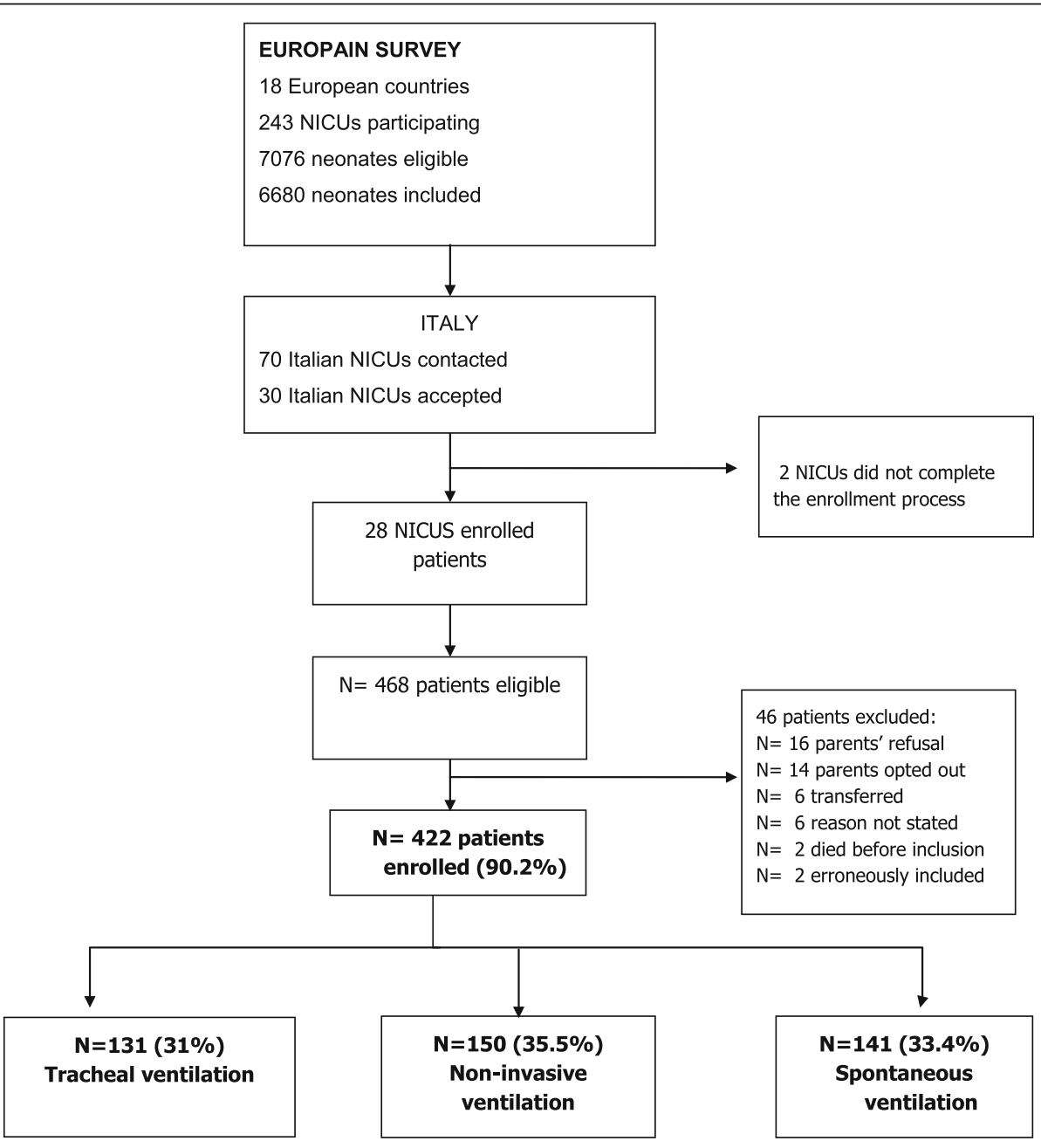

Fig. 1 Study flowchart 
Table 1 Demographics of the study population

\begin{tabular}{|c|c|c|c|c|c|}
\hline & $\begin{array}{l}\text { Total } \\
(n=422)\end{array}$ & Invasive ventilation $(n=131)$ & $\begin{array}{l}\text { Noninvasive ventilation } \\
(n=150)\end{array}$ & $\begin{array}{l}\text { Spontaneous ventilation } \\
(n=141)\end{array}$ & $p$ \\
\hline $\begin{array}{l}\text { Gestational age (weeks) } \\
\text { median (IQR) }\end{array}$ & $34.0(31.0-37.0)$ & $\begin{array}{l}31.0 \\
(27.0-36.0)\end{array}$ & $\begin{array}{l}33.0 \\
(31.0-35.0)\end{array}$ & $\begin{array}{l}35.0 \\
(34.0-38.0)\end{array}$ & $<.0001$ \\
\hline Gestational age (weeks) & & & & & $<.0001$ \\
\hline 24-29 N (\%) & $86(20.4)$ & $59(45.0)$ & $25(16.7)$ & $2(1.4)$ & \\
\hline 30-32 N (\%) & $76(18.0)$ & $19(14.5)$ & $45(30.0)$ & $12(8.5)$ & \\
\hline 33-36 N (\%) & $150(35.6)$ & $22(16.8)$ & $57(38.0)$ & $71(50.4)$ & \\
\hline 37-42 N (\%) & $110(26.1)$ & $31(23.7)$ & $23(15.3)$ & $56(39.7)$ & \\
\hline $\begin{array}{l}\text { Gestational age (weeks) } \\
\leq 32 \mathrm{~N}(\%)\end{array}$ & $162(38.4)$ & $78(59.5)$ & $70(46.7)$ & $14(9.9)$ & $<.0001$ \\
\hline $\begin{array}{l}\text { Birth weight (g) } \\
\text { median (IQR) }\end{array}$ & $\begin{array}{l}1921 \\
(1368-2739)\end{array}$ & $\begin{array}{l}1600 \\
(896-2550)\end{array}$ & $\begin{array}{l}1878 \\
(1367-2430)\end{array}$ & $\begin{array}{l}2295 \\
(1835-3130)\end{array}$ & $<.0001$ \\
\hline $\begin{array}{l}\text { Sex } \\
\text { male N (\%) }\end{array}$ & $226(53.6)$ & $82(62.6)$ & $77(51.3)$ & $67(47.5)$ & 0.0356 \\
\hline Born in same hospital as NICU, n (\%) & $345(81.8)$ & $93(71.0)$ & $133(88.7)$ & $119(84.4)$ & 0.0004 \\
\hline $\begin{array}{l}\text { Type of delivery } \\
\text { Caesarean, } \mathrm{n}(\%)\end{array}$ & $300(71.1)$ & $96(73.3)$ & $119(79.3)$ & $85(60.3)$ & 0.0013 \\
\hline $\begin{array}{l}\text { Age at admission (h) } \\
\text { median (IQR) }\end{array}$ & $0.4(0-3.3)$ & $0.5(0-3.2)$ & $0.2(0-0.6)$ & $0.5(0-19.1)$ & 0.0017 \\
\hline $\begin{array}{l}\text { CRIB score } \\
\text { median (IQR) }\end{array}$ & $0(0-1)$ & $2(1-5)$ & $0(0-1)$ & $0(0-1)$ & $<.0001$ \\
\hline $\begin{array}{l}\text { APGAR score at } 5 \text { min } \\
\text { Median (IQR) }\end{array}$ & $9(8-10)$ & $7(6-9)$ & $8(8-9)$ & $10(9-10)$ & $<.0001$ \\
\hline Intubated on admission, n (\%) & 79 (18.7) & $79(60.3)$ & NA & NA & NA \\
\hline $\begin{array}{l}\text { Duration of IV (hours) } \\
\text { median (IQR) }\end{array}$ & NA & $\begin{array}{l}71.7 \\
(16.8-157.0)\end{array}$ & NA & NA & NA \\
\hline $\begin{array}{l}\text { Duration of NIV (hours) } \\
\text { median (IQR) }\end{array}$ & NA & $\begin{array}{l}N=101 \\
120 \\
(33.0-262.8)\end{array}$ & $\begin{array}{l}N=150 \\
36.1 \\
(16.9-113.2)\end{array}$ & NA & NA \\
\hline $\begin{array}{l}\text { Status at discharge } \\
\text { Dead, } \mathrm{n}(\%)\end{array}$ & $14(3.3)$ & $12(9.2)$ & $1(0.7)$ & $1(0.7)$ & $<.0001$ \\
\hline $\begin{array}{l}\text { Days of participation in trial } \\
\text { median (IQR) }\end{array}$ & $15(7-28)$ & $28(13-28)$ & $17(8-28)$ & $9(5-15)$ & 0.0001 \\
\hline $\begin{array}{l}\text { Days of hospitalization } \\
\text { median (IQR) }\end{array}$ & $15(7-28)$ & $25(13-47)$ & $17.0(8-28)$ & $8.5(5-15)$ & $<.0001$ \\
\hline
\end{tabular}

Values were missing for some variables. NA Not applicable, CRIB Clinical Risk Index for Babies, IV invasive ventilation, NIV noninvasive ventilation, SV spontaneous ventilation

Parents had unlimited access to the unit $24 \mathrm{~h}$ a day in 10 [36\%] NICUs.

\section{Use of analgesia and sedation}

The use of A/S varied greatly among NICUs, ranging from $5.3-100 \%$ of all NICU admissions $(p<.0001)$, and from $50 \%-100 \%$ in infants on invasive ventilation $(p=0.0809)$.

We separately quantified the use of strong analgesics (morphine, fentanyl and ketamine), sedatives (midazolam, propofol), mild analgesics (paracetamol and local anesthetics) in the three differently ventilated groups, and the use of muscle relaxants only for the IV group, as shown in Table 2.
In the IV group, most infants $(70.8 \%)$ were given continuous or continuous $\mathrm{A} / \mathrm{S}$ plus boluses, while this was true of only $30.8 \%$ of infants in the NIV group $(69.2 \%$ were given boluses of $\mathrm{A} / \mathrm{S}$ ).

In IV infants, fentanyl infusions lasted a mean $\pm \mathrm{SD}$ of $184.5 \pm 193.2 \mathrm{~h}$, morphine was given for $95.9 \pm 59.6 \mathrm{~h}$, and midazolam for $117.2 \pm 111.0 \mathrm{~h}$. The use of neuromuscolar blockers was limited to $7(1.7 \%)$ patients, with a mean infusion duration of $72.6 \pm 85.4 \mathrm{~h}$.

We documented much the same use of A/S at Italian NICUs (35.4\%) as elsewhere in Europe (34.3\%), be it for all admissions or by type of ventilation (IV $86.3 \%$ vs 81.2, NIV $17.3 \%$ vs $17.8 \%$, and SV $7.1 \%$ vs $9.4 \%$ in Italy and other European countries, respectively). Significant 
Table 2 Use of analgesia and sedation by type of ventilation

\begin{tabular}{|c|c|c|c|c|c|}
\hline & $\begin{array}{l}\text { Total } \\
(N=422) \\
n(\%)\end{array}$ & $\begin{array}{l}\text { Invasive ventilation } \\
(N=131) \\
\mathrm{n}(\%)\end{array}$ & $\begin{array}{l}\text { Noninvasive ventilation } \\
(N=150) \\
N(\%)\end{array}$ & $\begin{array}{l}\text { Spontaneous ventilation } \\
(N=141) \\
\mathrm{n}(\%)\end{array}$ & $p$ \\
\hline Use of analgesia and/or sedation & $149(35.3)$ & $113(86.3)$ & $26(17.3)$ & $10(7.1)$ & $<.0001$ \\
\hline \multicolumn{6}{|l|}{ Method of administration: } \\
\hline Bolus only & $54(36.2)$ & $33(29.2)$ & $18(69.2)$ & $3(30)$ & \multirow[t]{3}{*}{0.0035} \\
\hline Continuous only & $34(22.8)$ & $28(24.8)$ & $4(15.4)$ & $2(20)$ & \\
\hline Continuous and bolus & $61(40.9)$ & $52(46.0)$ & $4(15.4)$ & $5(50)$ & \\
\hline Strong analgesics ${ }^{\mathrm{a}}$ & $137(32.5)$ & $109(83.2)$ & $21(14.0)$ & $7.0(5.0)$ & $<0.0001$ \\
\hline Morphine & $11(2.6)$ & $11(8.4)$ & $0(0.0)$ & $0(0.0)$ & $<0.0001$ \\
\hline Fentanyl & $131(31.0)$ & $103(78.6)$ & $21(16.0)$ & $7(5.3)$ & $<0.0001$ \\
\hline Ketamine & $2(0.2)$ & $2(1.5)$ & $0(0.0)$ & $0(0.0)$ & 0.0959 \\
\hline Sedatives $^{\mathrm{a}}$ & $45(10.7)$ & $35(26.7)$ & $5(3.3)$ & $5(3.6)$ & $<0.0001$ \\
\hline Propofol & $5(1.2)$ & $4(3.1)$ & $1(0.7)$ & $0(0.0)$ & 0.0434 \\
\hline Midazolam & $38(9.0)$ & $29(22.1)$ & $4(2.7)$ & $5(3.5)$ & $<0.0001$ \\
\hline Mild analgesics $^{a}$ & $16(3.8)$ & $9(6.9)$ & $4(2.7)$ & $3(2.1)$ & 0.0823 \\
\hline Paracetamol & $14(3.3)$ & $8(6.1)$ & $3(2.0)$ & $3(2.1)$ & 0.1369 \\
\hline Local anesthetics & $2(0.5)$ & $1(0.8)$ & $1(0.7)$ & $0(0.0)$ & 0.7619 \\
\hline Neuromuscolar blockers & $7(1.7)$ & $7(5.3)$ & NA & NA & NA \\
\hline Drug withdrawal & $4(2.8)$ & $4(3.6)$ & $00(0.0)$ & $00(0.0)$ & 1.000 \\
\hline Pain assessment & $285(67.5)$ & $112(85.5)$ & $101(67.3)$ & $72(51.1)$ & $<0.0001$ \\
\hline
\end{tabular}

a only the main medications are described in detail

differences in the mode of $\mathrm{A} / \mathrm{S}$ administration emerged, however, with Italian NICU's making less use of continuous infusions (CI) plus boluses in infants on IV (CI + Bolus: $n=948$ [58.1\%], ITA $n=52$ [46,0\%], only CI: EU $n=266$ [16,3\%], ITA $n=28$ [24,8\%], only bolus: EU $n=419$ [25.7\%], ITA $n=33$ $[29,2 \%], p=0.0212)$, and of intermittent boluses alone in those on NIV (CI + bolus: EU $n=10$ [4,2\%], ITA $n=4$ [15,4\%], only CI: EU $n=1$ [0,4\%], ITA $n=4[15,4 \%]$, only bolus EU $n=229$ [95,4\%], ITA $n=18$ [69,2\%], $p<0.0001$ ) and SV $(\mathrm{CI}+$ bolus: EU $n=29[10,7 \%]$, ITA $n=5[50,0 \%]$, only CI: EU $n=8$ [2,9\%], ITA $n=2$ [20,0\%], only bolus EU $n=235[86,4 \%]$, ITA $n=3[30,0 \%], p<0.0001)$ than in the rest of Europe.

Figure 2 shows A/S practices in Italy versus elsewhere in Europe, by mode of administration.

\section{Use of analgesia and sedation by gestational age}

The demographic characteristics of the very low birth weight infants born at less than 33 weeks of gestation are given in a supplemental table (Additional file 1: Table S1).

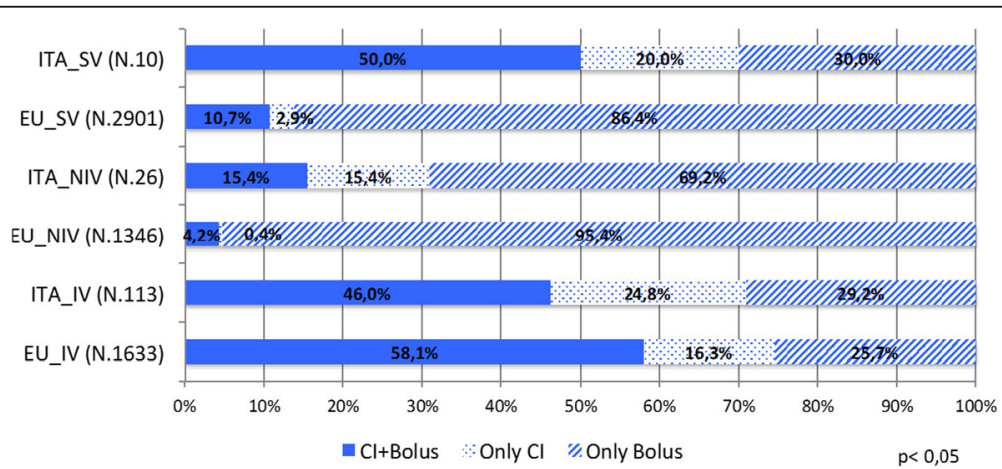

Fig. 2 Analgesia and sedation in Italy and in all participating countries in Europe by type of ventilation. EU include: Austria, Belgium, Cyprus, Estonia, Finland, France, Germany, Greece, Lithuania, Malta, Netherlands, Norway, Poland, Portugal, Spain, Sweden, United Kingdom. Chi-square test $p<0.001$ 
Data on the type of $\mathrm{A} / \mathrm{S}$ and their mode of administration were also analyzed by gestational age group (Table 3 ).

\section{Drug withdrawal practices}

Opioids and benzodiazepines were administered in 149 (35.3\%) of the 422 infants - 113 on IV (86.3\%), 26 (17.3\%) on NIV, and $10(7.1 \%)$ on SV groups - and they were weaned off the medication gradually in 59 (52.2\%), $13(50.0 \%)$ and $4(40 \%)$ cases, respectively $(p=0.6782)$. A drug withdrawal scale was used in 38 cases $(26.2 \%)$ overall - 33 on IV (29.2\%), 4 on NIV (10.4\%), and 1 on SV $(10.0 \%)(p=0.2349)$; and withdrawal was treated or prevented in 5 (4.4\%), 1 (3.8\%), and 0 cases, respectively. Drug withdrawal was diagnosed in 4 (3.6\%) infants, who were monitored and treated with various drugs, such as methadone, morphine, phenobarbital and benzodiazepines (diazepam, midazolam, lorazepam).

\section{Non-pharmacological interventions}

We also documented any concomitant use of sweet solutions as an adjuvant pain control measure. Almost one in two $(n=227[53,8 \%])$ of the infants admitted to an NICU received sweet solutions (more often sucrose than glucose), with no difference between the three ventilation groups: IV $n=69$ (52.6\%), NIV $n=88$ (58.7\%), SV $n=70(49.6 \%),(p=0.2900)$.

\section{Pain assessment}

Bedside PA using pain scales was recorded for 285 (67.5\%) neonates in all groups- 112 on IV (85.5\%), 101 on NIV $(67.3 \%)$, and $72(51.1 \%)$ on SV groups $(p<.0001)$. They were used more often in Italy than in the rest of European countries $(p<.0001)$, though some other countries reported assessing larger proportions of infants $(88 \%$ in France, $80 \%$ in the Netherlands). Figure 3 shows the frequency of PA performed in Italy vis-à-vis the rest of Europe for the three types of ventilation.

Regarding algometric tools, prolonged pain scales were used more often than acute pain scales. The EDIN scale was used in $78.6 \%$ of cases, and the Comfort-Comfort "behavior" scale only rarely (4.6\%), the PIPP in $10.9 \%$ of cases, the CRIES in $7.7 \%$, the indirect VAS in $7.4 \%$, and the NIPS in $5.3 \%$. The variability between NICUs concerning this parameter was high, and 20 of the 28 (71.4\%) units performed PA. The mean \pm SD number of PA per infant per day was $2.99 \pm 5.04$.

\section{Factors associated with use of analgesia/sedation and pain assessment}

Judging from our logistic regression model, the factors promoting the use of some form of $\mathrm{A} / \mathrm{S}$ included: more severe illness, as defined by higher CRIB scores (CRIB, OR $1.46,95 \%$ CI $1.20-1.77, p=0.0002$ ), invasive ventilation (IV vs SV OR 62.59, 95\% CI 22.01-177.97, NIV vs SV OR 2.60, 95\% CI 1.02-6.61 $p<0.0001)$, bedside pain assessment with a scale (OR 5.38, 95\%CI 1.69-17.16), and a number of bed below 15 (OR 3.55 95\%CI 1.08-11.69) (Table 4). The factors promoting the use of PA, on the other hand, were: gestational age below 33 weeks (OR 8.13, 95\% CI 2.64-25.03, $p=0.0003$ ), invasive ventilation (IV vs SV OR 163.03, 95\% CI 19.35- + $)$, NIV vs SV OR 6.06, 95\% CI $2.17-16.95, p<0.0001)$ and presence of a pain team (OR 114.35, 95\% CI 1.04- + ) (Table 5).

\section{Discussion}

In this study, we analyzed the bedside pain control practices adopted at Italian NICUs, based on data collected for the prospective, multicenter EUROPAIN study. The use of $\mathrm{A} / \mathrm{S}$ in the neonatal period is poorly documented and few surveys have reported on the type

Table 3 Type of analgesia and sedation, and their mode of administration by gestational age group

\begin{tabular}{|c|c|c|c|c|c|c|c|}
\hline & \multicolumn{2}{|c|}{$\begin{array}{l}\text { Total } \\
n=422\end{array}$} & \multicolumn{2}{|c|}{$\begin{array}{l}24-32 \mathrm{GA} \\
n=162\end{array}$} & \multicolumn{2}{|c|}{$\begin{array}{l}33-42 \text { GA } \\
n=260\end{array}$} & \multirow[t]{2}{*}{$P$} \\
\hline & N. & $\%$ & $\mathrm{~N}$ & $\%$ & N. & $\%$ & \\
\hline Use of analgesia and/or sedation & 149 & 35.3 & 87 & 53.7 & 62 & 23.8 & 0.001 \\
\hline \multicolumn{8}{|l|}{ Mode of A/S administration } \\
\hline Bolus only & 54 & 36.2 & 37 & 42.5 & 17 & 27.4 & 0.1671 \\
\hline Continuous only & 34 & 22.8 & 18 & 20.7 & 16 & 25.8 & \\
\hline Bolus + continous & 61 & 40.9 & 32 & 36.8 & 29 & 46.8 & \\
\hline \multicolumn{8}{|l|}{ Type of drugs } \\
\hline Fentanyl $^{a}$ & 131 & 31.0 & 80 & 49.4 & 51 & 19.6 & $<.0001$ \\
\hline Morphine $^{a}$ & 11 & 2.6 & 3 & 1.9 & 8 & 3.1 & 0.5424 \\
\hline Midazolam ${ }^{a}$ & 38 & 9.0 & 15 & 9.3 & 23 & 8.9 & 0.8854 \\
\hline Paracetamol & 14 & 3.3 & 9 & 5.6 & 5 & 1.9 & 0.0427 \\
\hline Neuromuscular blocker & 7 & 1.7 & 3 & 1.9 & 4 & 1.5 & 1.0000 \\
\hline
\end{tabular}

${ }^{a}$ continous and/or bolus administration in all three ventilation groups 


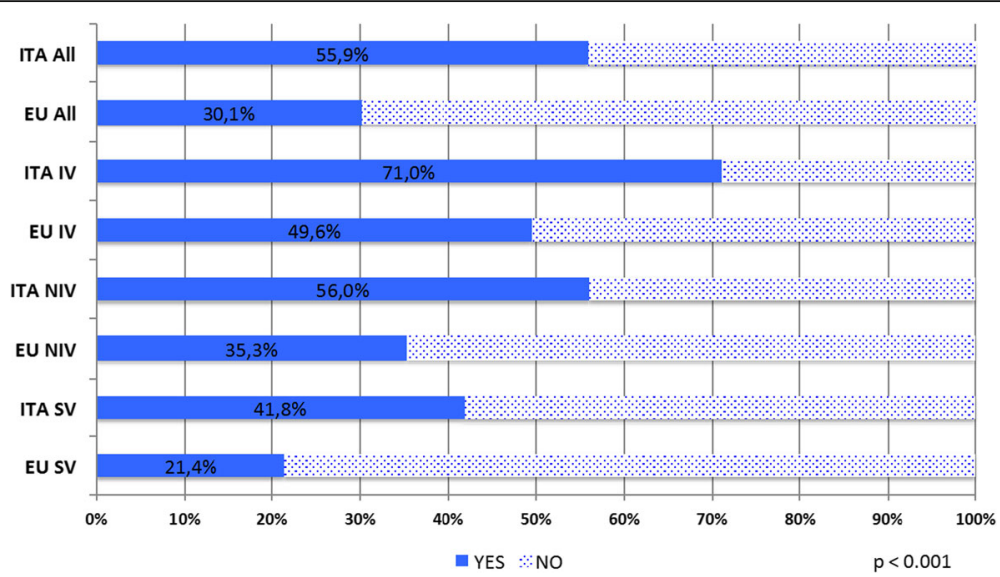

Fig. 3 Pain assessment in Italy and all participating countries in Europe. EU include: Austria, Belgium, Cyprus, Estonia, Finland, France, Germany, Greece, Lithuania, Malta, Netherlands, Norway, Poland, Portugal, Spain, Sweden, United Kingdom. ITA = pain assessment in Italian NICU admissions, PA_EU = pain assessment in other European NICU admissions, IV = pain assessment in invasive ventilation group, NIV = pain assessment in non-invasive ventilation group, $\mathrm{SR}=$ pain assessment in spontaneous ventilation group. Chi-square test $p<0.001$

and frequency of the drugs used or on any pain assessments performed [3,18-20]. Thus, this is the first Italian study that documents actual (not declarative) NICU practices regarding sedation and analgesia

We found that $35.3 \%$ of all infants admitted to the $\mathrm{NICU}$ in Italy received some form of A/S in the first 28 days of life. This applied mainly to patients on invasive ventilation (86.3\% of cases, as opposed to $17.3 \%$ of those on NIV, and $7.1 \%$ of those on SV). Strong analgesics were given, at least once, to $83.2 \%$ of infants on IV, and sedatives to one in three of them. There was a marked variability in the use and mode of administration of $\mathrm{A} / \mathrm{S}$ medication from one NICU to another. Pain assessment was documented for most NICU admissions (67.5\%), but here again the situation varied considerably - and pain is clearly still far from being widely considered as the fifth vital sign.

In a previous study of ours on this topic, pharmacological interventions were reportedly used routinely in newborn on invasive and noninvasive mechanical ventilation at $87 \%$ and $26 \%$ of Italian NICUs, respectively [20]. The present report certainly better reflects day-to-day clinical practice, and our findings for Italy are consistent with the picture seen elsewhere in Europe. Some differences emerge in the types of drug used, however. In Italy, fentanyl is preferred to morphine (used in $78.6 \%$ and $8.4 \%$,

Table 4 Univariate and multivariate logistic regression models for factors promoting the use of analgesia sedation

\begin{tabular}{|c|c|c|c|c|}
\hline \multirow[t]{2}{*}{ Predictors of analgesia/sedation } & \multicolumn{2}{|c|}{ Univariate } & \multicolumn{2}{|c|}{ Multivariate } \\
\hline & $p$-value & OR $(95 \% \mathrm{Cl})$ & $p$-value & OR $(95 \% \mathrm{Cl})$ \\
\hline Gestational age (weeks) $\leq 32$ & $<.0001$ & $3.54(2.15-5.83)$ & & \\
\hline CRIB score & $<.0001$ & $2.03(1.66-2.48)$ & 0.0002 & $1.46(1.20-1.77)$ \\
\hline Asphyxia, APGAR $<5$ at $5^{\prime}$ & $<.0001$ & $33.17(6.17-178.29)$ & & \\
\hline Sex, female & 0.2999 & $0.78(0.49-1.25)$ & & \\
\hline Born in same hospital as NICU & 0.0307 & $0.497(0.26-0.96)$ & & \\
\hline \multicolumn{5}{|l|}{ Type of ventilation } \\
\hline Invasive vs Spontaneous & $<.0001$ & $117.16(43.88-312.82)$ & $<.0001$ & $62.59(22.01-177.97)$ \\
\hline Noninvasive vs Spontaneous & & $2.61(1.14-5.98)$ & & $2.60(1.02-6.61)$ \\
\hline Use of pain scales & $<.0001$ & $19.04(5.92-61.19)$ & 0.0046 & $5.38(1.69-17.16)$ \\
\hline Pain specialist physician & 0.2891 & $0.50(0.14-1.81)$ & & \\
\hline Pain specialist nurse & 0.1111 & $0.41(0.14-1.23)$ & & \\
\hline Pain management team & 0.4972 & $1.42(0.52-3.91)$ & & \\
\hline Local guidelines for pain assessment & 0.8953 & $1.10(0.27-4.55)$ & & \\
\hline NICU beds ( $\leq 15$ beds vs $>15$ beds) & 0.0089 & $3.68(1.39-9.77)$ & 0.0372 & $3.55(1.08-11.69)$ \\
\hline Number of NICU admission & 0.0677 & $0.99(0.98-1.00)$ & & \\
\hline
\end{tabular}


Table 5 Univariate and multivariate logistic regression models for factors promoting the use of pain assessments

\begin{tabular}{|c|c|c|c|c|}
\hline \multirow[t]{2}{*}{ Predictors of pain assessment } & \multirow{2}{*}{$\begin{array}{l}\text { Univariate } \\
p \text {-value }\end{array}$} & \multicolumn{3}{|l|}{ Multivariate } \\
\hline & & OR $(95 \% \mathrm{Cl})$ & $p$-value & OR $(95 \% \mathrm{Cl})$ \\
\hline Gestational age (weeks) $\leq 32$ & $<.0001$ & $14.05(5.39-36.63)$ & 0.0003 & $8.13(2.64-25.03)$ \\
\hline CRIB score & 0.0005 & $1.77(1.29-2.43)$ & & \\
\hline APGAR $<5$ at $5^{\prime}$ & 0.0381 & $12.14(1.15-128.49)$ & & \\
\hline Sex, female & 0.7335 & $0.90(0.50-1.63)$ & & \\
\hline Born in same hospital as NICU & 0.1091 & $0.47(0.18-1.19)$ & & \\
\hline Type of ventilation & $<.0001$ & & $<.0001$ & \\
\hline Invasive vs Spontaneous & & $253.33(33.88-+\infty)$ & & $163.03(19.35-+\infty)$ \\
\hline Noninvasive vs Spontaneous & & $10.86(4.01-29.40)$ & & $6.06(2.17-16.95)$ \\
\hline Pain specialist physician & 0.3706 & $4.51(0.17-123.10)$ & & \\
\hline Pain specialist nurse & 0.5546 & $2.36(0.14-41.10)$ & & \\
\hline Pain management team & 0.0342 & $16.51(1.23-221.03)$ & 0.0481 & $114.35(1.04-+\infty)$ \\
\hline NICU beds ( $\leq 15$ beds vs $>15$ beds) & 0.8749 & $0.81(0.06-11.61)$ & & \\
\hline Number of NICU admission & 0.1075 & $0.95(0.90-1.01)$ & & \\
\hline
\end{tabular}

respectively, of infants on IV). The pharmacokinetics of fentanyl make it an effective analgesic because of the faster onset and relatively short duration of its action, and it has more limited hypotensive effects than morphine, especially in more preterm infants.

Similar patterns of opioid use were reported in Spain (in $79.1 \%$ of infants on IV) and Germany (91.2\%), while morphine was the drug of choise in the UK (91.6\%), Cyprus (100\%), Lithuania (95.5\%) and the Netherlands (70.5\%). Sufentanil was only used in France (52.5\%) and Poland (38.0\%) [21], although the data available on its use in the newborn is still limited [23]. None of the infants enrolled in this study were treated with remifentanyl or alfentanyl at Italian NICUs, as in other european countries [3]. When a stronger sedative effect is needed, one in three newborn infants is given midazolam (mostly in association with opioids), despite the lack of clinical evidence to support its use in this setting [24, 25]. In particular the use of midazolam in preterm infants is not recommended as there are some concerns of its impact on neurological outcome [26]. Neuromuscular blockers are rarely used in Italy (in $6.2 \%$ of infants on IV, regardless of gestational age), unlike other European countries (UK 59.5\%, Norway 46.7\%, Belgium 41.2\%, Finland $35.4 \%)$. There is evidence to support the use of neuromuscular blockers to facilitate and expedite tracheal intubation [27, 28], while their use during the mechanical ventilation of the newborn is less well documented [29].

Regarding the mode of A/S administration, we documented NICU staff efforts to modulate the treatment, usually by combining continuous infusions with boluses. Only one in four neonates was treated with boluses alone, as recommended in the latest Italian guidelines, [26] especially for the less sick, more preterm infants, in an attempt to reduce their cumulative dose of opioids with no loss of optimal pain control [12]. This is because of reports on the use of strong analgesics early in life being correlated with potential neurodevelopmental deficits in later infancy and childhood. Preclinical studies have suggested that opioids have negative effects on brain maturation due to their interference in the processes of neural cell differentiation, proliferation and apoptosis [30]. In a rat model, early exposure to opiates resulted in lower levels of brain-derived neurotrophic factor, a marker of synaptic plasticity and a modulator of cognitive function [30]. The opiate most often studied is morphine, which has a debated impact on the neurodevelopment of human newborn. Follow-up at 5-7 years of a small subgroup of the NEOPAIN trial showed no differences in overall intelligence quotient, but children exposed to morphine were impaired on visual analysis and short-term memory, and had more social problems than controls given placebo [13, 14]. Subsequent assessments at age 8-9 years old did not confirm these impairments, however [31]. More recently, Zwicker et al. conducted a prospective cohort study, and reported that a 10-fold increase in morphine exposure was associated with a $5.5 \%$ reduction in cerebellar volume, which correlated with worse motor and cognitive outcomes [32]. There may have been a sizable enrollment bias in their study, however.

On the other hand, several studies have confirmed the long-term neurodevelopmental impact of repetitive neonatal pain. An altered myelination at school age was recently found to be associated with a larger number of invasive procedures during hospitalization for very preterm birth in children with no severe brain injury or neurosensory impairments; a lower intelligence quotient 
was also associated with a larger number of invasive procedures and an altered brain microstructure [5].

Continuing uncertainty regarding how to strike the right balance between such potential outcomes should prompt a more rational and customized clinical approach to the management of pain in newborn, as Diendl et al. recently explained [33].

Analgesia and sedation in newborn infants is justified for several reasons, to control the clinical instability caused by pain and stress, unsynchronized breathing and suboptimal ventilation [34], and to prevent pain sensitization, and the long-term effects of pain on the developing brain $[15,35]$.

A Cochrane review concluded that ongoing analgesia with opioids during mechanical ventilation in preterm and term newborn is effective in reducing pain and stress scores, and does not prolong ventilation, alter mortality rates or subsequent intelligence, motor function, or behavior, whereas there is not enough evidence to support the routine use of opioid therapy for ventilated newborn infants [36]. In other words, a judicious use should be made of strong analgesics and sedatives based on regular clinical and algometric assessments - as recommended in the Italian national guidelines. The goal is to use the minimum effective dose for the prevention of behavioral and physiological derangement due to uncontrolled pain and stress, thus reducing the cumulative dose required and its potential side efffects. This is hugely important because the more premature infants are, the more they are exposed to A/S, as highlighted in the present study.

Consistently with previous studies, our logistic regression analyses revealed independent associations between $\mathrm{A} / \mathrm{S}$ and type of ventilation, the use of PA [37], and illness severity [38].

The use of non-pharmacological interventions was not thoroughly documented in this study, but - in clinical practice - several methods are used in synergy with strong analgesics and sedatives to better control pain and stress, possibly sparing the infant the effects of opioids. We only documented the use of sweets solutions, administered to half of the infants in our sample, which can be helpful when administered during skin-pricking procedures to mitigate pain and thus reduce the need for additional $\mathrm{A} / \mathrm{S}$, in the more preterm infants at least.

Although the majority of Italian NICUs (82.1\%) reported routinely conducting pain assessments, only $67 \%$ of all newborn infants admitted had a PA $(85.0 \%$ of those on invasive ventilation). In the present survey, $71.4 \%$ of NICUs performed PA, and this represents an improvement over the 2012 survey, when only one in three NICUs reported doing so. Factors associated with the use of PA were a lower gestational age, invasive ventilation and the presence of a pain team. The Italian national guidelines recommend, however, routine pain assessment in all infants at least three times a day (during every nursing shift), and the outcome should be documented in the patient's medical records, as also required by a national law (Lg N. 38/2010 on access to palliative care and pain therapy). This is an aspect of neonatal care that still needs to be improved. The proper use of PA could make pain treatments more appropriate, and needs to be encouraged. Pain assessments were based mainly on the use of tools for measuring prolonged pain (EDIN, Comfort, ...) - in $78.6 \%$ of cases - whereas acute pain scales (PIPP, NIPS,CRIES) were used in only one in three cases. In clinical practice in the NICU setting, a validated scale for prolonged pain is probably more appropiate.

In interpreting our results it is important to bear in mind some limitations of our survey. First, although 28 of the 70 invited NICUs participated, most NICUs represented the northern part of Italy, but not the south of the country, thus giving us only a partial picture of NICU practices nationwide. Second, we recorded neither the dosage of the medication administered, nor all the nonpharmacological interventions that might be used (apart from sweet solutions), so we learned little about any integrated approaches to pain and stress adopted at Italian NICUs (as recommended in the national guidelines). We can also draw no conclusions on the appropriateness of the pain control measures adopted from our survey. Unfortunately, using a more complex questionnaire in an effort to collect more data would have negatively affected compliance and given rise to issues with incomplete data.

\section{Conclusion}

We documented a generally widespred use of A/S and PA in Italy, albeit with a marked diversity between different NICUs and for infants on different types of ventilation. The recently-published national guidelines provide more advice on a judicious and appropriate use of $\mathrm{A} / \mathrm{S}$, along with recommendations for routine pain assessment and a more customized, safe and effective pain control in such a vulnerable patient population. Our data will allow us to monitor the evolution of $\mathrm{A} / \mathrm{S}$ and PA practices following the latest national guidelines.

\section{Additional file}

Additional file 1: Table S1. Demographics of the study population < 33 weeks gestational age. (DOC 55 kb)

\section{Abbreviations}

A/S: Analgesia/Sedation; AAP: American Academy of Pediatrics; Cl: Continous infusion; CRIB: Clinical Risk Index for Babies; IV: Invasive ventilationNICU, Neonatal Intensive Care Unit; NIV: Noninvasive ventilation; PA: Pain Assessment; SV: Spontaneous ventilation

\section{Acknowledgments}

The authors gratefully acknowledge the contributions of the physicians, nurses, and other health care providers at the participating institutions. 
We thank all the sub-investigators at the NICUs: Anna Pirelli (Monza), Carlo Poggiani (Cremona), Valeria Fasolato (Milano), Gloria Cristofori (Milano), Serena Gomirato (Treviso), Michela Alfiero Bordigato (Camposampiero), Paolo Biban (Verona), Alessandra Bertolini (Verona), Rosanna Golin (Vicenza), Franco Elena (Trento), Grazia Molinaro (Bolzano), Federica Visintini (Udine), Roberto Rossini (Bologna), Elisabetta Garetti (Modena), Michela Faraoni (Pisa), Simone Pratesi (Firenze), Cristina Germini (Perugia), Annabella Braguglia (Roma), Benigni Gina (Roma), Adriano Azzali (Agrigento), Barresi Santina (Reggio Calabria), Daniele Merazzi (Como), Giuseppe Carrera (Lodi), Gina Ancora (Rimini), Patrizia Savant Levet (Torino), Tonia Cossu (Sassari), Melli Nives (Reggio Emilia). We also thank Valentina Favero for her support in the data analysis.

\section{Funding}

This study received no funding.

\section{Availability of data and materials}

The datasets generated and analyzed during the present study are available from the corresponding author or from the European coordinator (RC) on reasonable request.

\section{Authors' contributions}

PL and RP conducted the study and collected important background information. PL drafted the manuscript. AC made substantial contributions to the analysis and interpretation of the data, and performed the statistical analysis. AC, EB, JR were involved in drafting the manuscript and revising it critically for important intellectual content. RC, AKJS, EC made substantial contributions to the conception and design of the study. PL, EC, RC and AKJ made substantial contributions to the data acquisition and interpretation. All authors read and approved the final manuscript.

\section{Competing interests}

The authors declare that they have no competing interests.

\section{Consent for publication}

The parents of partecipanting infants consented also for data pubblication.

\section{Ethics approval and consent to partecipate}

After obtaining the approval of the regulatory bodies for the Protection of Human Subjects, Data Protection, and Health Research Data Management in France, the study was also approved by the local ethical committees of the participating hospitals. Written informed consent was obtained from the parents of the infants involved

\section{Author details}

'Neonatal Intensive Care Unit, Women's and Children's Health Department, Azienda Ospedaliera-University of Padova, Via Giustiniani 3, Padua 35128, Italy. ${ }^{2}$ Department of Cardiac, Thoracic and Vascular Sciences, University of Padua, Padua, Italy. ${ }^{3}$ Hôpital Amand Trousseau, Service des Urgences Pédiatrique, Paris, France. ${ }^{4}$ Hôpital Amand Trousseau, Service de Réanimation Pédiatrique et Néonatale, Paris, France. ${ }^{5}$ Departments of Pediatrics, Anesthesiology, Perioperative and Pain Medicine, Stanford University School of Medicine, Stanford, CA, USA. ${ }^{6}$ Université Pierre at Marie Curie, Faculté de Médecine, Paris, France.

\section{Received: 17 September 2016 Accepted: 1 February 2017}

Published online: 07 March 2017

\section{References}

1. Anand KJS, Hickey PR. Pain and its effects in the human neonate and fetus. N Engl J Med. 1987;317:1321-9.

2. Anand KJ, Hickey PR. Halothane-morphine compared with high-dose sufentanil for anesthesia and postoperative analgesia in neonatal cardiac surgery. N Engl J Med. 1992;326:1-9.

3. Carbajal R, Rousset A, Danan C, Coquery S, et al. Epidemiology and treatment of painful procedures in neonates in intensive care units. JAMA. 2008;300:60-70.

4. Taddio A, Katz J, Ilersich AL, Koren G. Effect of neonatal circumcision on pain response during subsequent routine vaccination. Lancet. 1997; 349:599-603.
5. Vinall J, Miller SP, Bjornson BH, Fitzpatrick KP, et al. Invasive procedures in preterm children: brain and cognitive development at school age. Pediatrics. 2014;133:412-21.

6. Grunau RE, Whitfield MF, Petrie-Thomas J, Synnes AR, et al. Neonatal pain, parenting stress and interaction, in relation to cognitive and motor development at 8 and 18 months in preterm infants. Pain. 2009;143:138-46.

7. Anand KJ, Palmer FB, Papanicolaou AC. Repetitive neonatal pain and neurocognitive abilities in ex-preterm children. Pain. 2013;154:1899-901.

8. Zwicker JG, Grunau RE, Adams E, Chau V, et al. Score for neonatal acute physiology-II and neonatal pain predict corticospinal tract development in premature newborns. Pediatr Neurol. 2013;48:123-9. e1.

9. Anand KJ, Hall RW, Desai N, Shephard B, et al. NEOPAIN Trial Investigators Group. Effects of morphine analgesia in ventilated preterm neonates: primary outcomes from the NEOPAIN randomised trial. Lancet. 2004;363:1673-82.

10. Davidson A, Flick RP. Neurodevelopmental implications of the use of sedation and analgesia in neonates. Clin Perinatol. 2013;40:559-73.

11. Dong C, Anand KJ. Developmental neurotoxicity of ketamine in pediatric clinical use. Toxicol lett. 2013;220:53-60.

12. Ancora G, Lago P, Garetti E, Pirelli A, et al. Efficacy and safety of continuous infusion of fentanyl for pain control in preterm newborn on mechanical ventilation (MV). J Pediatr. 2013;163(3):645-51.

13. Ferguson SA, Ward WL, Paule MG, Hall RW, Annad KJ. A pilot study of preemptive morphine analgesia in preterm neonates: effects on head circumference, social behavior, and response latencies in early childhood. Neurotoxicol Teratol. 2012;34(1):47-55.

14. de Graaf J, van Lingen RA, Simons SH, Anand KJ, et al. Long-term effects of routine morphine infusion in mechanically ventilated neonates on children's functioning: five-year follow-up of a randomized controlled trial. Pain. 2011; 152(6):1391-7.

15. Anand KJS, International Evidence-Based Group for neonatal pain Consensus statement for the prevention and management of pain in the newborn. Arch Pediatr Adolesc Med. 2001;155:173-80.

16. Lago P, Merazzi D, Garetti E, Pieragostini L, et al. Guidelines for procedural pain in the newborn. Acta Pediatrica. 2009:98:932-9.

17. American Academy of Pediatrics, Committee on fetus and newborn and section on anesthesiology and pain medicine. Prevention and management of procedural pain in the neonate: an update. Pediatrics. 2016;137(2): e20154271. doi:10.1542/peds

18. Lago P, Guadagni A, Merazzi D, Ancora G, et al. Pain management in the neonatal intensive care unit: a national survey in Italy. Paediatr Anaesth. 2005;15:925-31

19. Lago P, Boccuzzo G, Garetti E, Pirelli, et al. Pain management during invasive procedures at Italian NICUs: has anything changed in the last five years? J Matern Fetal Neonatal Med. 2012;25:148-50.

20. Lago P, Garetti E, Ancora G, Merazzi D, for the Pain Study Group of the Italian Society of Neonatology, et al. Procedural pain in neonates: the state of the art in the implementation of national guidelines in Italy. Pediatr Anesth. 2013;23(5):407-14.

21. Carbajal R, Eriksson M, Courtois E, Boyle E, et al. Sedation and analgesia practices in neonatal intensive care units (EUROPAIN): results from a prospective cohort study. Lancet Respir Med. 2015:3(10):796-812.

22. Lund GC, Green D, Browne R, Ackerman N. New CRIB Score: one score for all NICU admissions. Pediatr Res. 1997:41:162.

23. Schmidt B, Adelmann C, Stutzer H, et al. Comparison of sufentanil versus fentanyl in ventilated term neonates. Klin Padiatr. 2010:222:62-6.

24. $\mathrm{Ng} \mathrm{E}$, Taddio A, Ohlsson A. Intravenous midazolam infusion for sedation of infants in the neonatal intensive care unit. Cochrane Database Syst Rev. 2012;6, CD002052

25. Koch SC, Fitzgerald M, Hathway GJ. Midazolam potentiates nociceptive behavior, sensitizes cutaneous reflexes, and is devoid of sedative action in neonatal rats. Anesthesiology. 2008;108:122-9.

26. Lago P, Garetti E, Pirelli A, Merazzi D, et al. Linee Guida per la prevenzione ed il trattamento del dolore nel neonato. Edizioni Biomedia giugno. 2016.

27. Demsey EM, Hazzani Al F, Faucher D, Barrington KJ. Facilitation endotracheal intubation with mivacurium and fentanyl in the neonatal intensive care unit. Arch Dis Child Fetal Neonatal Ed. 2006;91:F279-282.

28. Lemyre B, Cheng R, Gaboury I. Atropine, fentanyl and succinylcholine for non-urgent intubations in newborns. Arch Dis Child Fetal Neonatal Ed. 2009;94(6):F439-442.

29. Alexander SM, Todres ID. The use of sedation and muscle relaxation in the ventilated infants. Clin Perinatol. 1998;25(1):63-78. 
30. Rozisky JR, Laste G, de Macedo IC, Santos VS, et al. Neonatal morphine administration leads to changes in hippocampal BDNF levels and antioxidant anzyme activity in the adult life rats. Neurochem Res. 2013;38(3):494-503.

31. De Graaf J, Van Lingen RA, Valkenburg AJ, Weisglas-Kuperus N, et al. Does neonatal morphine use affect neuropsychological outcomes at 8 to 9 years of age? Pain. 2013;154:449-58.

32. Zwicker JG, Miller SP, Grunau RE, Chau V, et al. Smaller cerebellar growth and poorer neurodevelopmental outcomes in very preterm infants exposed to neonatal morphine. J Pediatr. 2016;172:81-7.

33. Deindl $P$, Giordano V, Fuiko $R$, Waldhoer $T$, Unterasinger $L$, Berger $A$, et al. The implementation of systematic pain and sedation management has no impact on outcome in extremely preterm infants. Acta Paediatr. 2016;105:798-805.

34. Dyke MP, Kohan R, Evans S. Morphine increases synchronous ventilation in preterm infants. J Paediatr Child Health. 1995;31:176-9.

35. Grunau RE. Neonatal pain in very preterm infants: long-term effects on brain, neurodevelopment and pain reactivity. Rambam Maimonides Med J. 2013;4, e0025

36. Bellù $\mathrm{R}$, de Waal WK, Zanini R. Opioids for neonates receiving mechanical ventilation. Cochrane Database Syst Rev. 2008;23(1):CD004212.

37. Taylor BJ, Robbins JM, Gold Jl, Logsdon TR, Bird TM, Anand KJS. Assessing postoperative pain in neonates: a multicenter observational study. Pediatrics. 2006;118:e992-1000.

38. Bhandari V, Bergqvist LL, Kronsberg SS, Barton BA, Anand KJ. Morphine administration and short-term pulmonary outcomes among ventilated preterm infants. Pediatrics. 2005;116:352-9.

\section{Submit your next manuscript to BioMed Central} and we will help you at every step:

- We accept pre-submission inquiries

- Our selector tool helps you to find the most relevant journal

- We provide round the clock customer support

- Convenient online submission

- Thorough peer review

- Inclusion in PubMed and all major indexing services

- Maximum visibility for your research

Submit your manuscript at www.biomedcentral.com/submit 